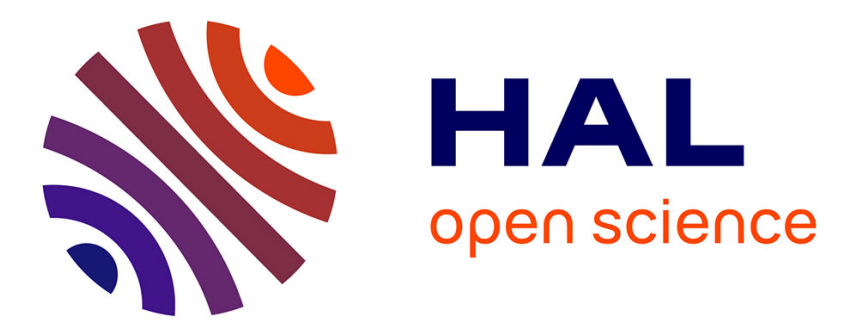

\title{
Impact of cold conditions on diesel injection processes of biodiesel blends
}

\author{
P. Tinprabath, C. Hespel, S. Chanchaona, Fabrice Foucher
}

\section{To cite this version:}

P. Tinprabath, C. Hespel, S. Chanchaona, Fabrice Foucher. Impact of cold conditions on diesel injection processes of biodiesel blends. Renewable Energy, 2016, 96, pp.270-280. 10.1016/j.renene.2016.04.062 . hal-01597104

HAL Id: hal-01597104

https://hal-univ-orleans.archives-ouvertes.fr/hal-01597104

Submitted on 2 Mar 2021

HAL is a multi-disciplinary open access archive for the deposit and dissemination of scientific research documents, whether they are published or not. The documents may come from teaching and research institutions in France or abroad, or from public or private research centers.
L'archive ouverte pluridisciplinaire HAL, est destinée au dépôt et à la diffusion de documents scientifiques de niveau recherche, publiés ou non, émanant des établissements d'enseignement et de recherche français ou étrangers, des laboratoires publics ou privés.

\section{(c)(1)}

Distributed under a Creative Commons Attribution| 4.0 International License 


\title{
Impact of cold conditions on diesel injection processes of biodiesel blends
}

\author{
P. Tinprabath ${ }^{\mathrm{a},}{ }^{*}$, C. Hespel ${ }^{\mathrm{b}}$, S. Chanchaona ${ }^{\mathrm{c}}$, F. Foucher ${ }^{\mathrm{b}}$ \\ a Department of Mechanical Engineering, Rajamangala University of Technology Phra Nakhon, Bangkok 10800, Thailand \\ b Laboratoire PRISME, Université d'Orléans, INSA CVL, Orléans 45072, France

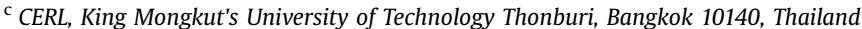

In this article, we report experimental results on the impact of cold conditions on diesel and biodiesel blends injection processes. We focus on cold conditions in view of the new Euro VI standards concerning problems related to cold-start. A Bosch CRI 3.1 piezoelectric injector was used on a typical diesel engine. Five fuel types were tested: diesel, winter diesel, diesel-biodiesel blends (B50), a winter diesel-biodiesel blend (B50(W)) and pure biodiesel (B100). Injection pressures of 30-60 MPa were tested (during start-up of the engine) in order to study the injection flow characteristics at room temperature and in cold conditions. Under cold conditions, the discharge coefficients for all fuels were lower than at room temperature. When the fraction of biodiesel in the blend increased, the discharge coefficients decreased slightly. Spray penetration increased and spray angle strongly decreased in cold conditions. This behavior was particularly clear for the B100 fuel. Winter diesel despite a higher viscosity than diesel showed most interesting performance in terms of discharge coefficient both at low temperature than at room tem-perature. These benefits disappear with the blend with biodiesel. New correlation coefficients for esti-mating the discharge coefficient and the spray angle are presented for cold conditions.

\section{Introduction}

Nowadays biodiesel, in particular blends with $2-20 \%$ diesel fuel, is increasingly used to partially replace fossil fuel $[1,2]$. The reason for the popularity of biodiesel is that biofuel is an agricultural product and a sustainable alternative energy source, it is environmentally friendly with reduced GHG emissions according to life cycle assessments (LCA), and has a higher cetane number and lower sulfur and aromatic contents [3]. The main disadvantages of biodiesel are its higher viscosity, lower energy content, higher cloud and pour points, higher nitrogen oxide (NOx) emissions, lower power and high price [1]. It is important to determine the viscosity evolution of biodiesel blends in cold conditions, especially during engine start-up. Pollutant emissions from biodiesel fuelled vehicles

\footnotetext{
* Corresponding author. Department of Mechanical Engineering, Rajamangala University of Technology Phra Nakhon, 1381 Pacharat1 Rd. Bangsue, Bangkok, Thailand..

E-mail addresses: padipan.t@rmutp.ac.th (P. Tinprabath), camille.hespel@univorleans.fr (C. Hespel), somchai.cha@kmutt.ac.th (S. Chanchaona), fabrice.foucher@ univ-orleans.fr (F. Foucher).
}

have received particular attention as in 2015 they have to respect Euro VI regulations. The new standards include cold-start problems, i.e. evaluation of post-treatment strategies and exhaust gas recirculation (EGR) at low temperature. The quality of the cold start at $-7{ }^{\circ} \mathrm{C}$ is an increasingly stringent constraint [4]. While dieselbiodiesel blends under $5 \%$ do not impact cold flow properties [5], the emissions due to the use of biodiesel may not meet the new European standards. It is therefore necessary to consider the use of biodiesel in cold conditions in vehicle engines [5-7], to determine the physical properties of injection and flow characteristics inside the injector, the spray tip penetration, spray angle and fuel atomization in order to improve the characteristics of biodiesel, the fuel injection method and thus achieve the highest engine efficiency and low emissions.

Under standard temperature conditions, many studies [6-11] have highlighted the influence of fuel properties on the performance of the injector. When the viscosity increases, the flow rate in the nozzle decreases slightly, favoring the appearance of larger drops in the spray atomization. However, a decrease in the discharge coefficient was not observed with biodiesel blends, only with pure biodiesel (B100) [12,13]. Research shows that it is not 
easy to find a relation between the fuel mass flow rate and temperature. It depends on the type of injector and type of fuel $[14,15]$. Under cold conditions, the discharge coefficient $(C d)$ decreases strongly with an increase in viscosity [4,14]. Kegl [16] studied a specific configuration (a single injection assembly of inline fuel injection) and the impact of temperature on biodiesel. He showed that when the temperature decreased the injection duration, injection timing, mean injection rate and injection pressure increased. Tinprabath et al. [4] studied the influence of biodiesel and diesel fuel blends on the injection rate under cold conditions, and demonstrated that the fuel viscosity changes the injection duration and hence for the same pulse duration it also changes the total mass injected. Moreover at low temperature the fuel begins to gel and then to crystallize. A first wax formation is observed at the cloud point and then the crystallization leads to clogging of filters and the malfunction of the pump (CFPP). Specific fuels were made to be distributed during most winters (Winter or Artic Diesel). Additives limit the agglomeration of crystals and allow obtaining a cloud point or CFFP much lower. Beyond this fact, what impact this type of fuel blended with biofuel on performance of the injector? It has been shown in a previous study [4] that the Winter Diesel despite a higher viscosity than Diesel showed most interesting performance in terms of discharge coefficient both at low temperature than at room temperature.

Several publications show that when the percentage of biodiesel is increased, spray tip penetration also increases and the spray angle decreases $[8,11,13,17,18]$. Increasing the viscosity increases the spray Sauter Mean Diameter (SMD) and reduces the atomization capacity [14]. According to the literature, biodiesel fuel produced from vegetable or animal oils can be used with diesel injectors. Payri et al. [19] observed the effect of fuel properties on diesel spray development in extreme cold conditions $\left(-18{ }^{\circ} \mathrm{C}\right)$, and found that the penetration length was clearly increased. Desantes et al. [11] studied three varieties of biodiesel produced from rapeseed: pure biodiesel (B100), and two biodiesel blends (5\% and 30\%). The results showed that only pure biodiesel had a negative impact on the spray behavior.

The main objective of this work is to study and to investigate at nearly $-7{ }^{\circ} \mathrm{C}$ following Euro VI regulations. In the present study, the chosen fuels were diesel fuel, winter diesel fuel, biodiesel (rapeseed biodiesel), diesel fuel 50\% rapeseed biodiesel, and winter diesel fuel blended with $50 \%$ rapeseed biodiesel. These mixtures are interesting because they have similar viscosities for different additives B50/B50W. The fuel properties were measured at the operating temperature and at $8{ }^{\circ} \mathrm{C}, 0{ }^{\circ} \mathrm{C},-5^{\circ} \mathrm{C}$, and $-8^{\circ}$. The novelty of the investigation is the study of fuel injection processes and the macroscopic behavior of the spray: opening delay, injection duration, discharge coefficient, penetration length of penetration and spray angle. The previously established correlations will be tested [6], the effect of winter additives will be discussed in the biodiesel blends.

\section{Experimental apparatus}

\subsection{Experimental setup}

Two experimental test rigs were used: an injection rate test rig and a visualization test rig. For the two experiments a prototype Bosch CRI 3.1 piezoelectric micro-sac injector with three convergent (an AR of 38\% following [20]) orifices $100 \mu \mathrm{m}$ in diameter with a pump and a pressure fuel tank were used $[6,12,13]$. All the injection and visualization equipment was installed in a climatic chamber to control the temperature in the experiment. Injection pressures were set at 30-60 MPa so as to be close to start-up conditions. The fuel injection rate was analyzed with an IAV ${ }^{@}$
Injection Rate system (model K-025-50) [21]. This system detects and processes the dynamic pressure generated by injection into tube loops filled with fuel. The duct is pressurized by an adjusted nitrogen supply until $2.5 \mathrm{MPa}$ as shown in Fig. 1. The injection rate is computed by Eq. (1), where $\dot{m}$ is the mass flow rate, $S_{\text {tube }}$ the cross sectional area of the tube, $a$ the fuel sound velocity and $p(t)$ the dynamic pressure.

$\dot{m}=\frac{S_{\text {tube }}}{a} p(t)$

Macroscopic visualization was accomplished using a constantvolume vessel with optical access and a constant circulation of air near the window as shown in Fig. 2. To obtain the desired density conditions inside the vessel, the pressure was adjusted; the system is designed for a maximum pressure of $3 \mathrm{MPa}$. The fuel injector is located at the top of the vessel. An 8-bit (256 gray levels) high speed camera (Photron ${ }^{@}$ PowerViewTMHS-2000) recording at 15,000 frames per second was used to capture the three sprays by Mie scattering. Illumination was provided by a continuous $150 \mathrm{~W}$ halogen lamp. The camera and lamp are outside the climatic chamber, only a fiber light is inside. The image processing is based on the work by Tinprabath et al. [6] and Dernotte et al. [13]. For each operating condition, 50 injections at a frequency of $1 \mathrm{~Hz}$ were recorded to ensure convergence of the results.

\subsection{Injection analysis}

The injection rate was analyzed following the method of Tinprabath et al. [6], Dernotte et al. [12], and Payri et al. [14,21]. The mean mass flow rate, $\dot{m}_{\text {measured }}$ from the quasi-steady state period 1000-2000 $\mu$ s after the start of activation (SOA) (Fig. 3) was used to calculate the discharge coefficient $C d$, by Eq. (2). This period avoids the transient phenomena related to the opening and closing phases of the injector $[6,12]$. The theoretical mass flow rate, $\dot{m}_{t h}$ (Eq. (3)) determined from the continuity equation (Eq. (4)) depends on the geometrical cross-section and the inlet velocity, $V_{\text {mean }}$ calculated with Bernoulli's equation (Eq. (5)):

$$
\begin{aligned}
& C d=\frac{\dot{m}_{\text {measured }}}{\dot{m}_{\text {th }}} \\
& \dot{m}_{\text {th }}=n_{\text {orifice }} \cdot S_{c} \sqrt{2 \Delta P \cdot \rho_{f}} \\
& \dot{m}_{\text {th }}=n_{\text {orifice }} \cdot \rho_{f} \cdot S_{c} V_{\text {th }} \\
& V_{\text {th }}=\sqrt{\frac{2 \Delta P}{\rho_{f}}} \\
& \text { Re }=\frac{V_{\text {mean }} \cdot D_{o}}{\nu} \\
& V_{\text {mean }}=\frac{\dot{m}_{\text {measured }}}{n_{\text {orifice }} \cdot S_{c} \cdot \rho_{f}}
\end{aligned}
$$

where $n_{\text {orifice }}$ is the number of orifices on the geometric crosssectional area of the orifice outlet, $\Delta P$ the pressure differential $(\Delta P=$ injection pressure, $P i$ - back pressure, $P b), \rho_{f}$ the fuel density at the experimental temperature, and $V_{t h}$ the theoretical velocity at the fuel outlet section. Re the Reynolds number is calculated by Eq. (6), where $V_{\text {mean }}$ is the fuel mean velocity at the orifice exit, $D_{0}$ is the geometric outlet diameter and $\nu$ is the kinematic viscosity of the fuel at the experimental temperature at atmospheric pressure. 


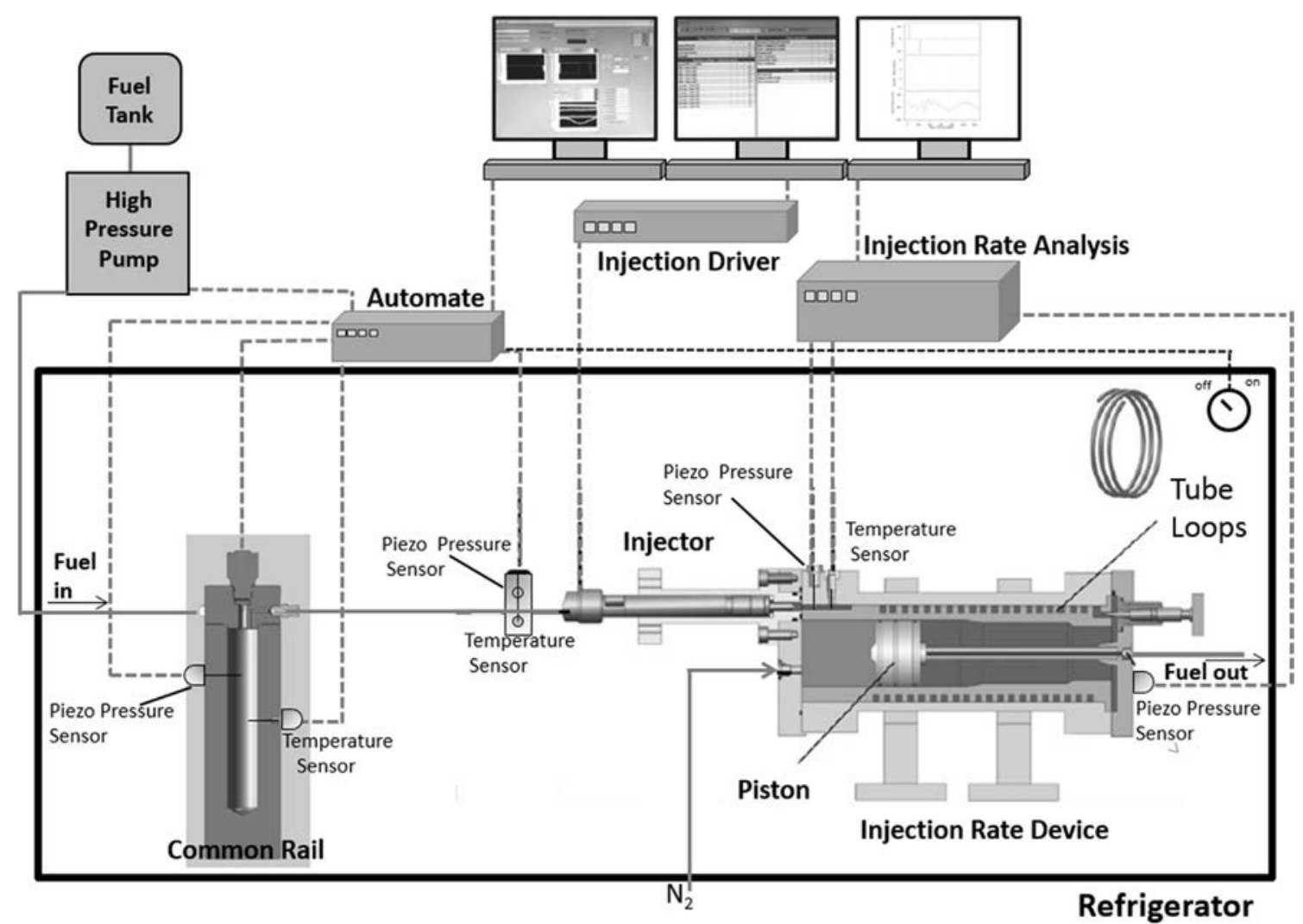

Fig. 1. Injection rate experimental setup (from IAV@ technical specification) $[4,6,12]$.

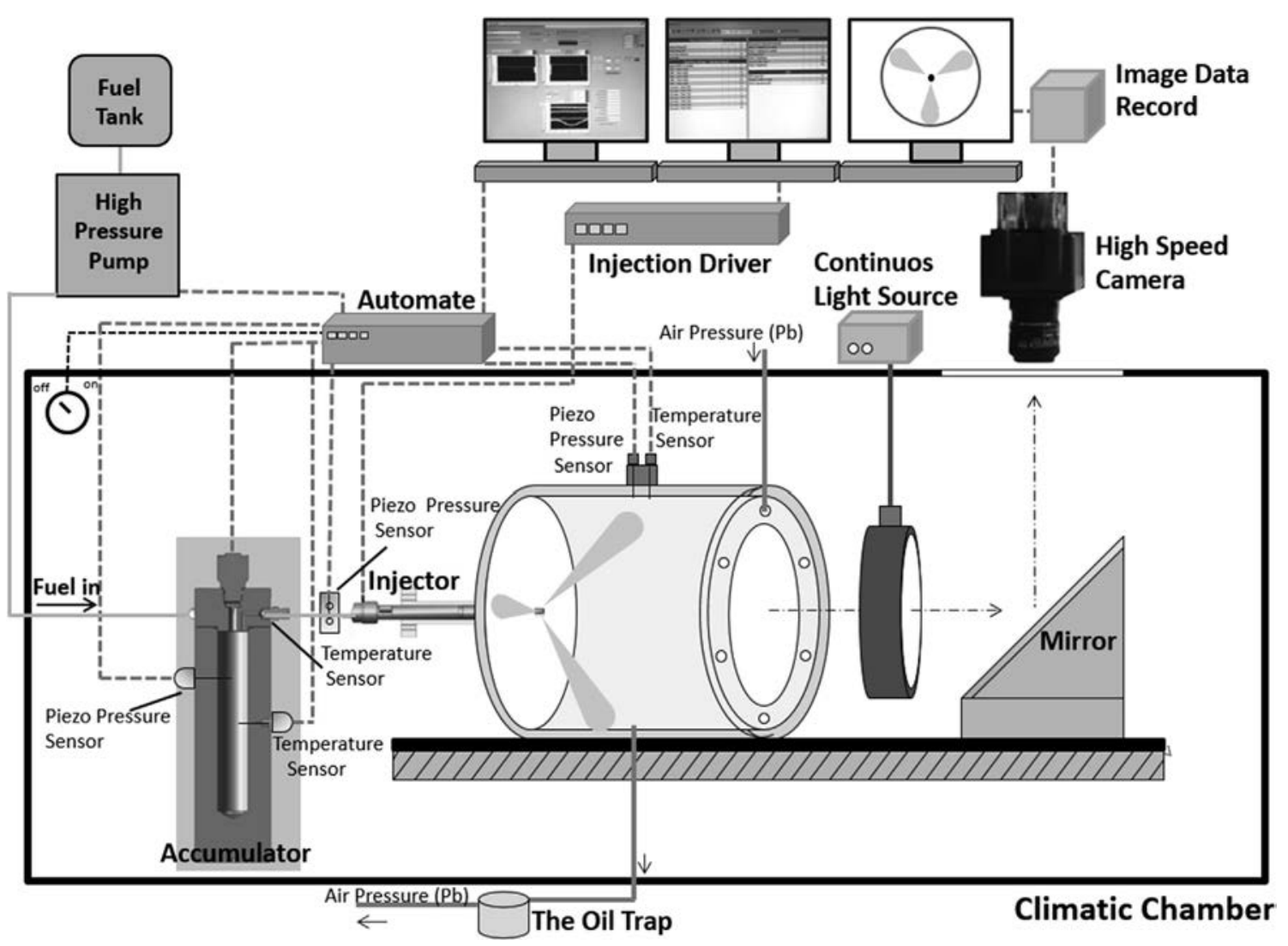

Fig. 2. Experimental setup for spray injection. 


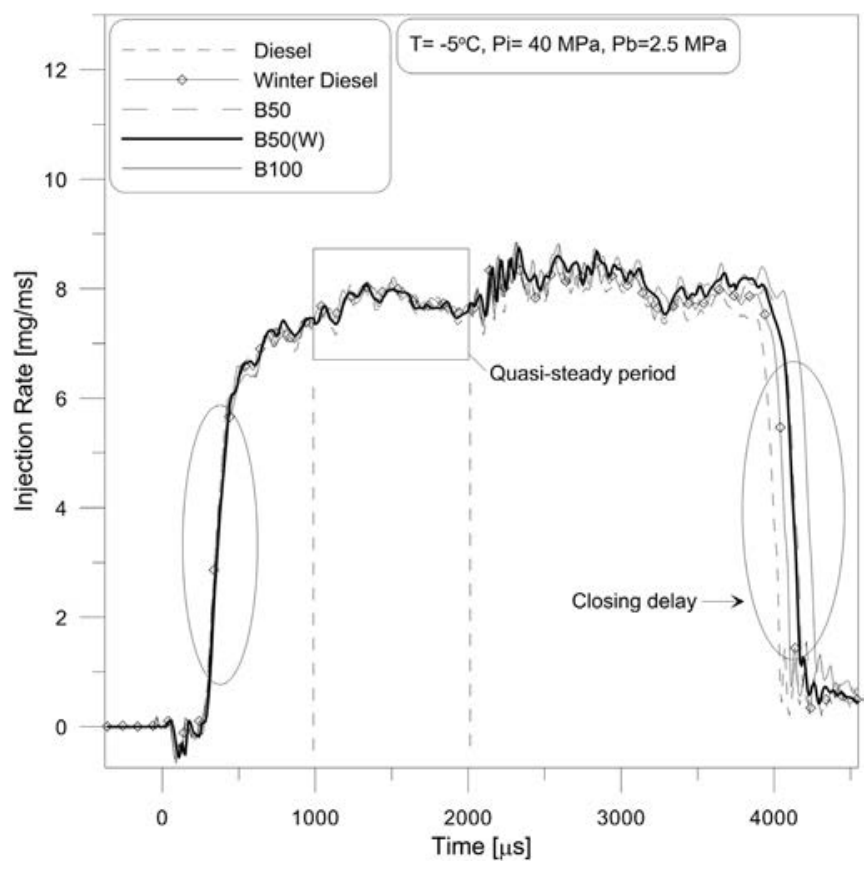

Fig. 3. Mean mass flow rate calculation window during the quasi-steady state period; all fuel, $P i=40 \mathrm{MPa}, \mathrm{Pb}=2.5 \mathrm{MPa}, \mathrm{T}=-5{ }^{\circ} \mathrm{C}$

$V_{\text {mean }}$, the fuel exit mean velocity (Eq. (7)) can be determined by measuring the mass flow rate and using the continuity equation. Assuming that the real cross-section of the injector outlet is equal to the geometric cross-sectional area $\left(S_{c}\right)$, i.e. that there is no flow contraction generated by cavitation phenomena [6,11], flow losses are attributed to losses of flow velocity. This lower velocity is the effective velocity of the fuel.

\subsection{Spray image analysis}

Raw images were analyzed using a digital image processing program to determine the spray tip penetration $S$ and spray angle $\theta$ at $S / 2$ [6]. In summary there are three main steps (Fig 4). First, the background is subtracted from the spray region and then it is converted to a negative image. Second, the image is binarized by applying an intensity threshold level according to the Otsu method [22] to "separate" the spray from the background. Third, from the digitized images, the spray tip penetration $S$ and spray area on half length $A$ are measured ( $A$ is projected area of the upstream half of the spray in an image). The spray angle is calculated with equation (8):

$\tan \left(\frac{\theta}{2}\right)=\frac{A}{(S / 2)^{2}}$

\subsection{Experimental test fuels}

The five fuels chosen in this study were as follows: diesel, winter diesel, B100 (100\% biodiesel produced from rapeseed), B50 (diesel $50 \%$, biodiesel 50\%) and B50(W) (winter diesel 50\%, biodiesel 50\%). The fuel density and viscosity were analyzed with an Anton Paar ${ }^{\circledR}$ Stabinger Viscosmeter (model SVM 3000/G2) [23]. The fuel properties are listed in Table 1.

These measurements were correlated with the correlation proposed by Riazi [24] for density and with new coefficient values in cold conditions [4] for viscosity. The results from experiment and correlation are shown in Fig. 5.

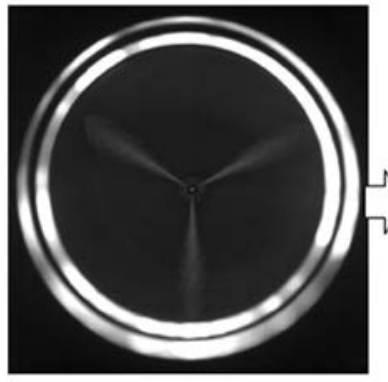

(a)

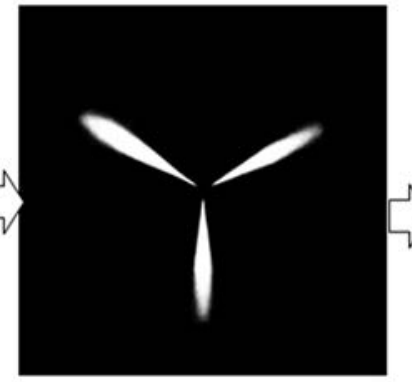

(b)

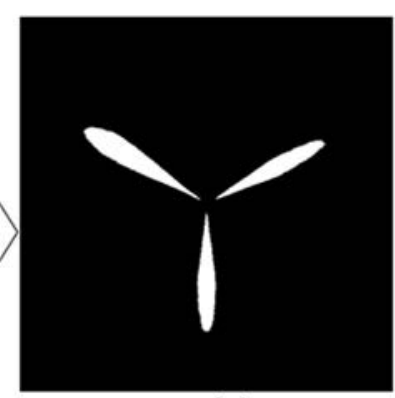

(c)

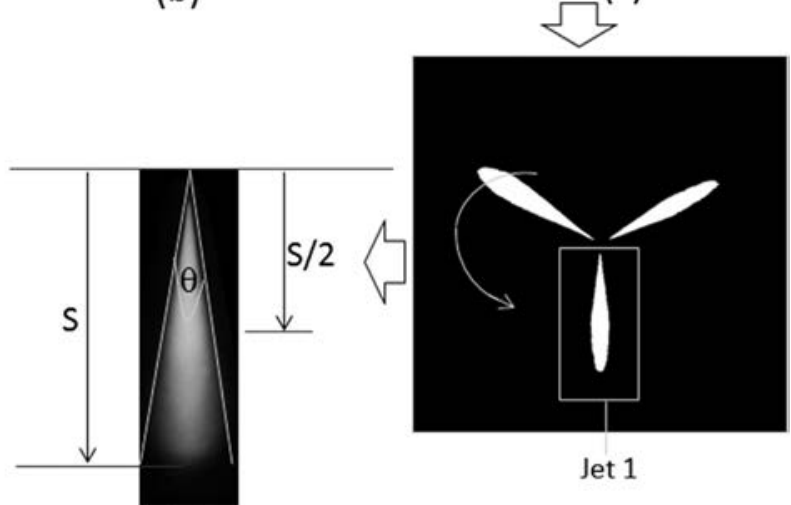

(d)

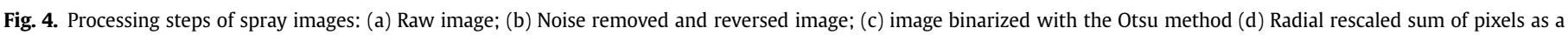
function of axial distance. 
Table 1

Fuel matrix in standard conditions.

\begin{tabular}{|c|c|c|c|c|c|c|c|c|c|c|}
\hline \multirow[t]{2}{*}{$\mathrm{T}\left({ }^{\circ} \mathrm{C}\right)$} & \multicolumn{5}{|c|}{ Density, $\rho_{f},\left(\mathrm{~kg} / \mathrm{m}^{3}\right)$} & \multicolumn{5}{|c|}{ Kinematic viscosity, $v\left(\mathrm{~mm}^{2} / \mathrm{s}\right)$} \\
\hline & Diesel [4] & Winter diesel [4] & B50 [4] & $\mathrm{B} 50(\mathrm{~W})$ & $\mathrm{B} 100[4]$ & Diesel [4] & Winter diesel [4] & B50 [4] & B50(W) & $\mathrm{B} 100[4]$ \\
\hline-8 & 855.1 & 853.5 & 877.4 & 876.4 & 900.2 & 10.38 & 11.43 & 15.42 & 14.36 & 19.72 \\
\hline-5 & 852.3 & 851.4 & 874.9 & 874.3 & 897.7 & 8.95 & 9.65 & 12.64 & 12.11 & 16.04 \\
\hline 0 & 848.8 & 847.4 & 871.1 & 870.8 & 894.1 & 7.51 & 8.04 & 9.95 & 10.09 & 13.03 \\
\hline 8 & 843.2 & 842.4 & 865.5 & 865.1 & 888.3 & 5.85 & 6.19 & 7.68 & 7.63 & 9.97 \\
\hline 20 & 834.7 & 834.1 & 856.9 & 856.5 & 879.6 & 4.23 & 4.43 & 5.49 & 5.53 & 7.05 \\
\hline \multicolumn{2}{|c|}{ Test method /Fuel } & \multicolumn{3}{|l|}{ B100 } & \multicolumn{3}{|l|}{ Diesel } & \multicolumn{3}{|c|}{ Winter diesel } \\
\hline \multicolumn{2}{|c|}{ EN $23015-$ CP } & \multicolumn{3}{|l|}{$-3^{\circ} \mathrm{C}$} & \multicolumn{3}{|l|}{$-5^{\circ} \mathrm{C}$} & \multicolumn{3}{|c|}{$-8^{\circ} \mathrm{C}$} \\
\hline \multicolumn{2}{|c|}{ EN 116 - CFPP } & \multicolumn{3}{|l|}{$-14^{\circ} \mathrm{C}$} & \multicolumn{3}{|l|}{$-20^{\circ} \mathrm{C}$} & \multicolumn{3}{|l|}{$-28{ }^{\circ} \mathrm{C}$} \\
\hline
\end{tabular}
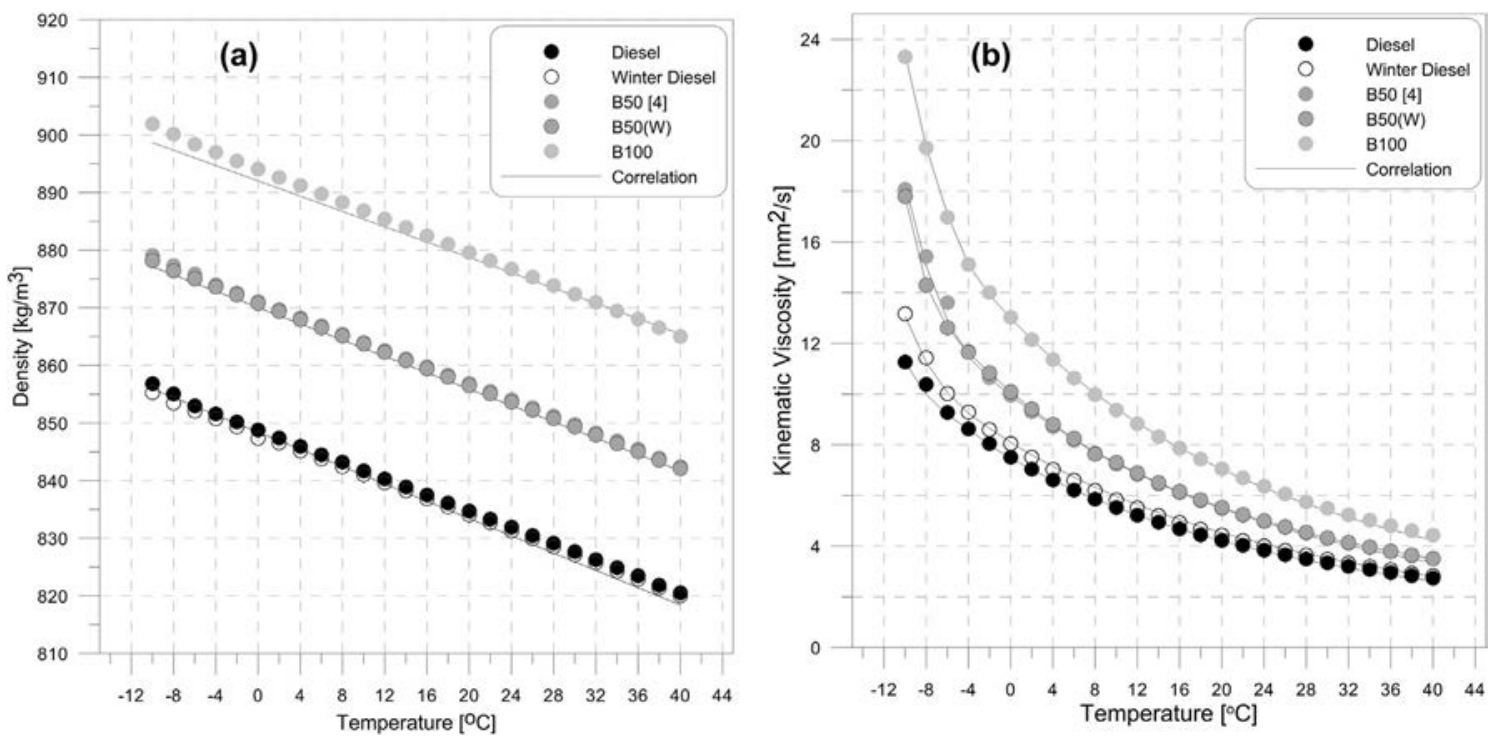

Fig. 5. Fuels properties experimental data \& correlation (a) Density and (b) Kinematic viscosity.

\subsection{Operating conditions}

For the injection rate experiment the temperature was set at Troom $\left(20^{\circ} \mathrm{C}\right), 8{ }^{\circ} \mathrm{C}, 0{ }^{\circ} \mathrm{C},-5^{\circ} \mathrm{C}$, and $-8{ }^{\circ} \mathrm{C}\left( \pm 0.5^{\circ} \mathrm{C}\right)$. Minus $8{ }^{\circ} \mathrm{C}$, Cloud point of winter diesel is the lowest operating temperature.

The injection pressure, $P i$, was selected during start-up of the engine and varied from 30 to $60 \mathrm{MPa}$. The back-pressure, $\mathrm{Pb}$, varied from 1 to $2.5 \mathrm{MPa}$ in order to study injection rate behavior. The duration of electrical activation of the injector was set at $2000 \mu \mathrm{s}$ for an effective injection duration of about $4000 \mu$ s Each injection event was reproduced 50 times. The injection frequency was set at $1 \mathrm{~Hz}$ to allow the pressure waves in the injection device and in the
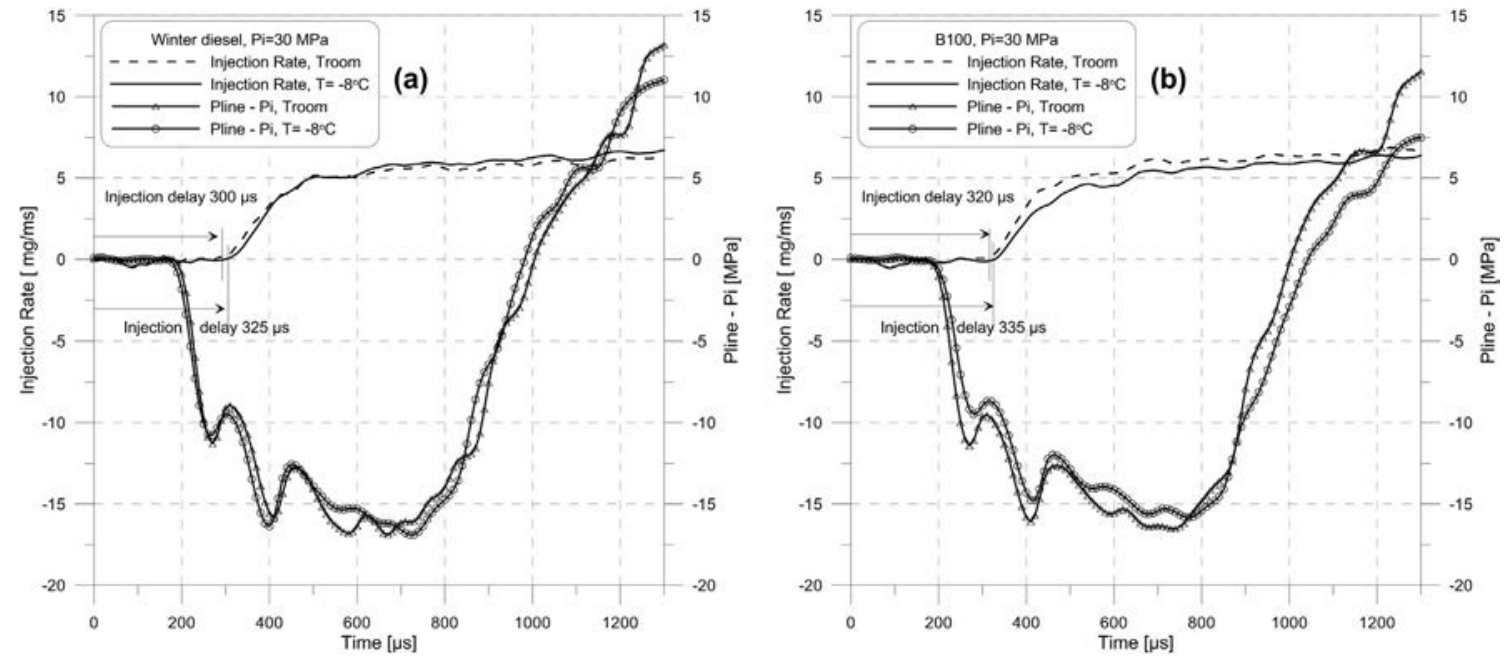

Fig. 6. Mean mass flow rate and Pline $-P i, P i=30 \mathrm{MPa}$ when (a) winter diesel and (b) B100. 

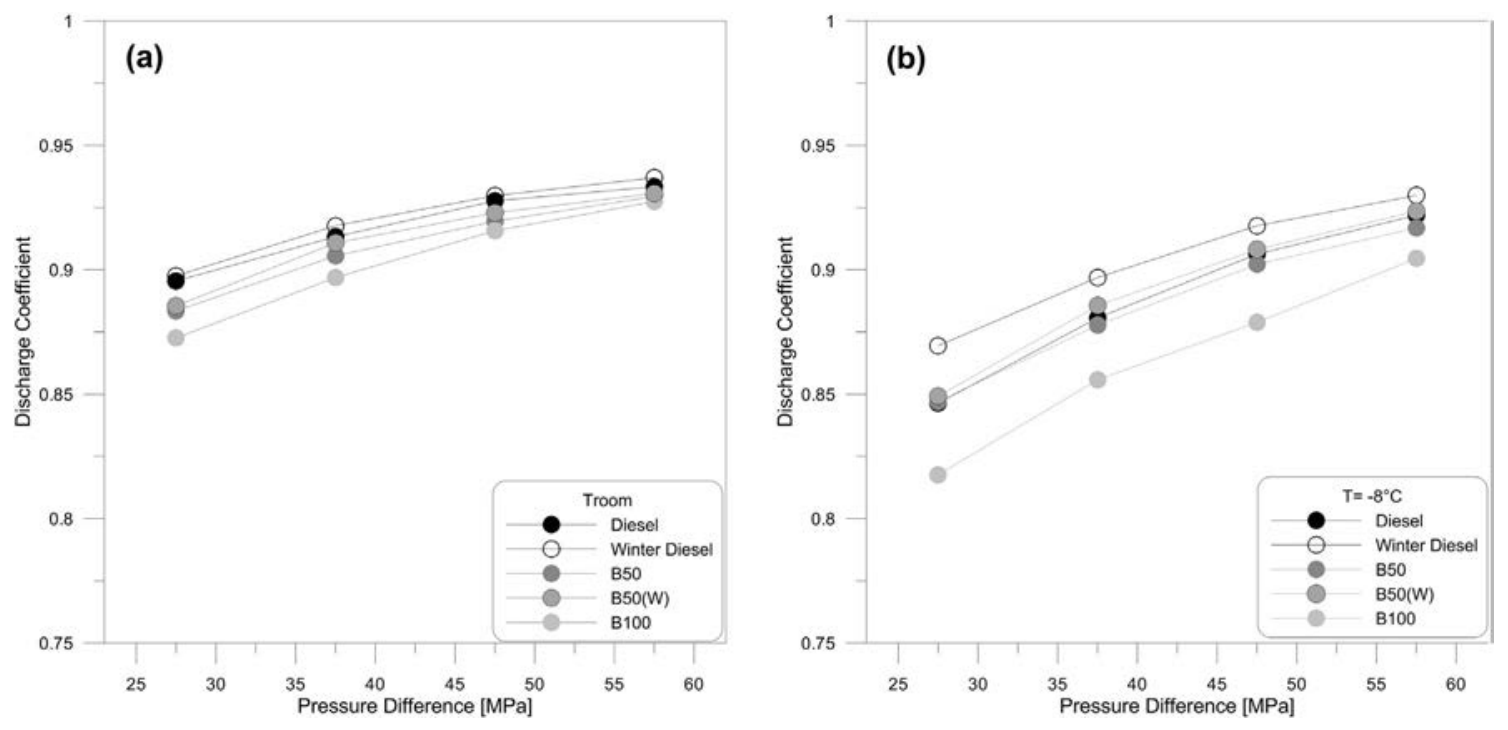

Fig. 7. Impact of fuel blends and temperature on the discharge coefficient $-P i=30-60 \mathrm{MPa}$ at (a) Troom and (b) $\mathrm{T}=-8{ }^{\circ} \mathrm{C}$.

duct upstream of the injector to be completely dampened [6,12].

Spray injection visualization was also conducted at room temperature and $-8{ }^{\circ} \mathrm{C}\left( \pm 0.5^{\circ} \mathrm{C}\right)$. The injection pressure, $P i$, varied from 30 to $60 \mathrm{MPa}$ and the back-pressure, $\mathrm{Pb}$, from 1.2 to $1.7 \mathrm{MPa}$ for a variation in density of $14.3-20.13 \mathrm{~kg} / \mathrm{m}^{3}$ representing the gas density at the Top Dead Centre (TDC) of conventional diesel engines. The duration of electrical activation of the injector was set at $2000 \mu \mathrm{s}$.

\section{Results and discussion}

3.1. Effect of cold temperature and blended fuel properties during injector opening and closing

With piezoelectric technology, involving strong activation of the needle, a change of fuel or of temperature only slightly modifies the opening of the injector. The delay depends on the valve and needle

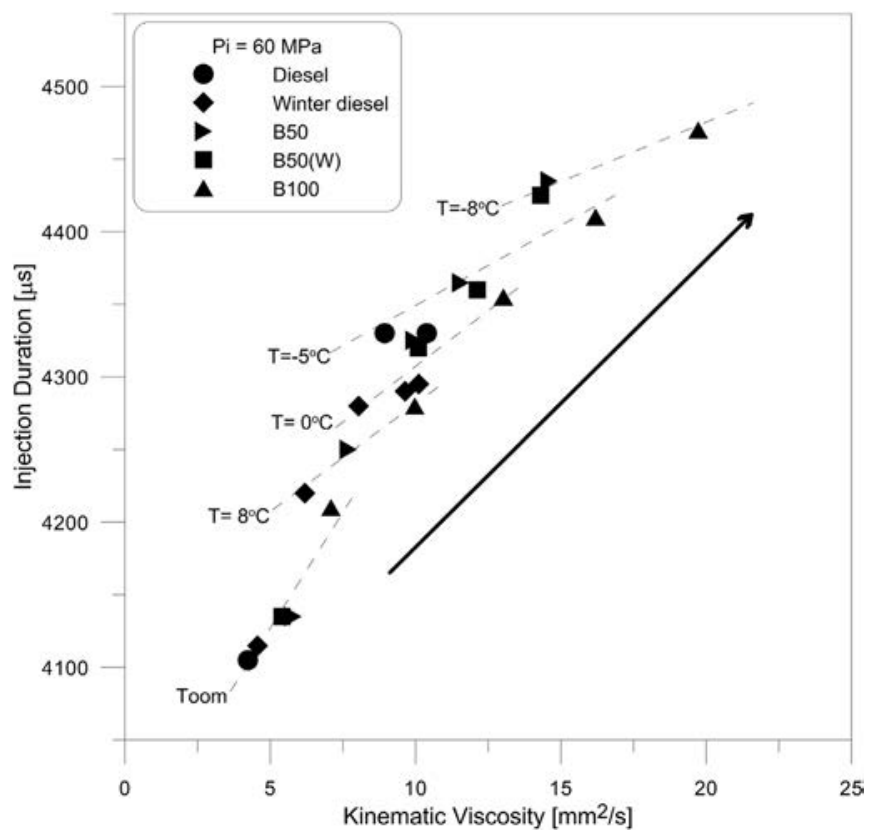

Fig. 8. Impact of fuel kinematic viscosity on the injection duration $-\mathrm{Pi}=60 \mathrm{MPa}$, $\mathrm{T}=$ Troom, $8{ }^{\circ} \mathrm{C},-5{ }^{\circ} \mathrm{C}$ and $-8{ }^{\circ} \mathrm{C}$. displacement. Fig. 6 shows the mean mass flow rate and variation of pressure upstream of the injector for winter diesel and B100 at $\mathrm{Pi}=30 \mathrm{MPa}$. The pressure drop is caused by the opening of the valve. The acoustic pressure waves are perturbed again (local maximum pressure around $300 \mu$ s) by now the lifting of the needle. With B100 at low temperature, the pressure decrease is slower and the lifting of the needle is slightly delayed which explains the $15 \mu \mathrm{s}$ increase in hydraulic delay. This shift is greater on closing than on opening, as shown on Fig. 6(b) (injection rate). However, changing the fuel and temperature has a strong impact on the closing delay as can be seen in Fig. 3. The closing delay of injection increases with the biodiesel content, with the B100 fuel showing the most delayed closing. This behavior is typical for this technology. With solenoid activation, the movement of the needle at a higher viscous fluid is

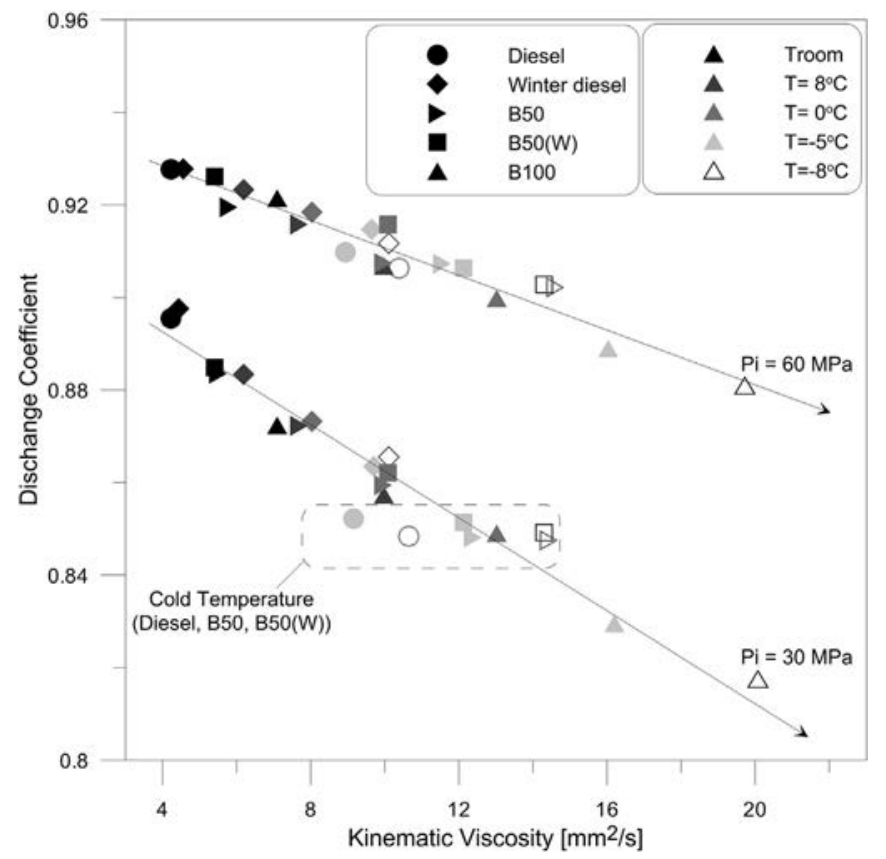

Fig. 9. Impact of fuel kinematic viscosity on the discharge coefficient $-\mathrm{Pi}=30$, $60 \mathrm{MPa}, \mathrm{T}=$ Troom, $8{ }^{\circ} \mathrm{C},-5^{\circ} \mathrm{C}$ and $-8{ }^{\circ} \mathrm{C}$. 

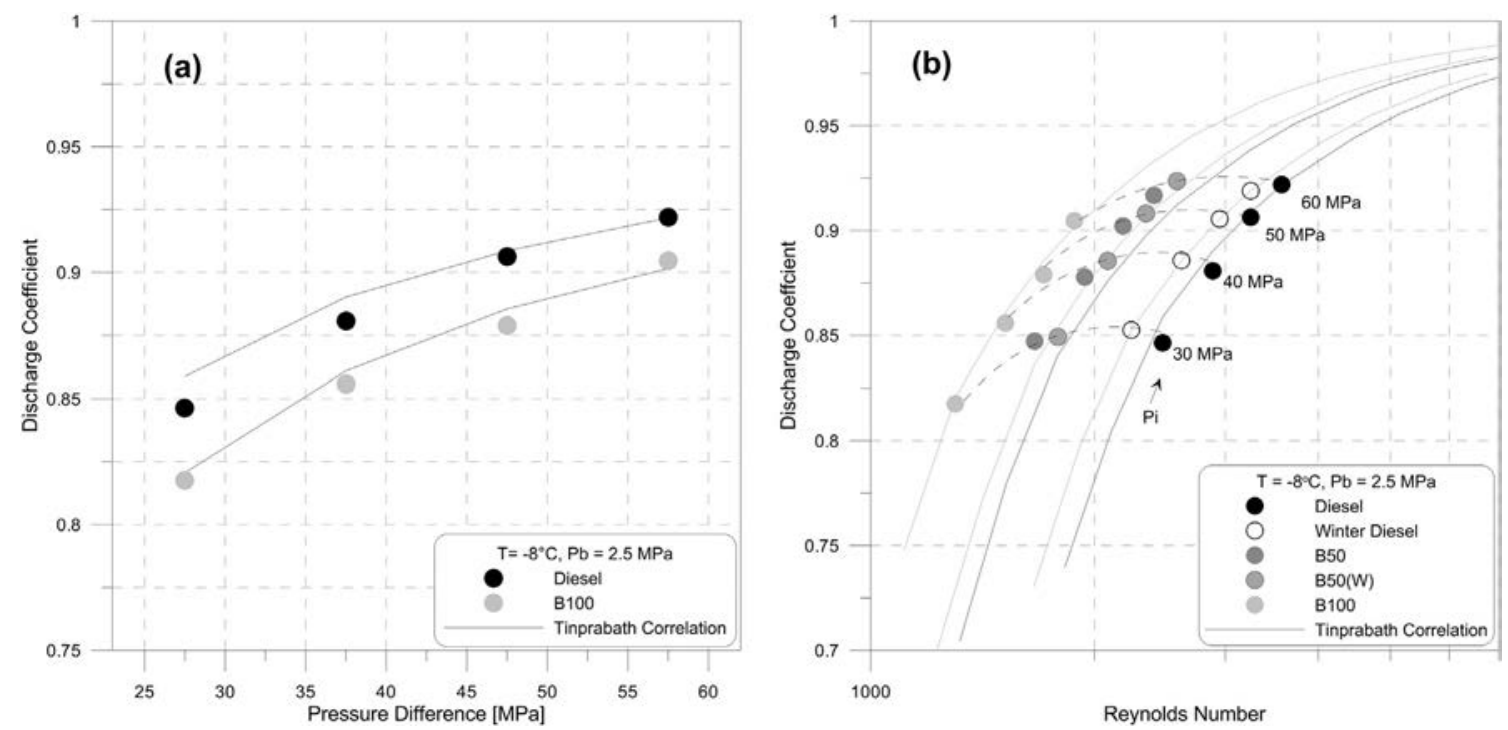

Fig. 10. Discharge coefficient: experimental results compared with the correlation as (a) function pressure difference and (b) function Reynolds number.

more difficult during the opening and closing of the injector [25]. The needle displacement due of pressure drop inside injector depends on frictional forces so on the viscosity of fuel B50/B50(W) with the same viscosity and a different additives show the same closing delay (The curves Fig. 3 for these fuel are perfectly combined). The additives don't modify the opening or closing delay. Only the viscosity pilots these aspects for all injection pressure. With decrease in temperature the viscosity of fuel increases. So the closing delay increases and leads to an increase of injection duration, like observed Fig. 8. The results are similar to the findings of Kegl [16].

\subsection{Discharge coefficient}

The data were analyzed according to Eq. (2). The results are given in Fig. 7(a) which shows the discharge coefficient versus the pressure difference for different fuels at room temperature. The discharge coefficient is affected by the biodiesel blend or increase in viscosity at room temperature. These decreases are greater for small injection pressures: $2.6 \%$ for $P i=30 \mathrm{MPa}$ and $0.6 \%$ for $P i=60 \mathrm{MPa}$. The results are similar to the findings of Seykens et al. [9], Desantes et al. [11], Park et al. [15] and Tinprabath et al. [6]. This behavior is confirmed even down to $0^{\circ} \mathrm{C}$. On Fig. 9 the $C d$ decreases linearly with viscosity at an injection pressure of $30 \mathrm{MPa}$. Likewise, Fig. 7(b) shows the discharge coefficient versus the pressure difference for different fuels at a temperature of $-8^{\circ} \mathrm{C}$, which is Cloud Point of winter diesel. The results show that the discharge coefficient of winter diesel fuel is the highest. No significant difference between the discharge coefficients of diesel or biodiesel blends was observed in the test range of injection pressures. However, the

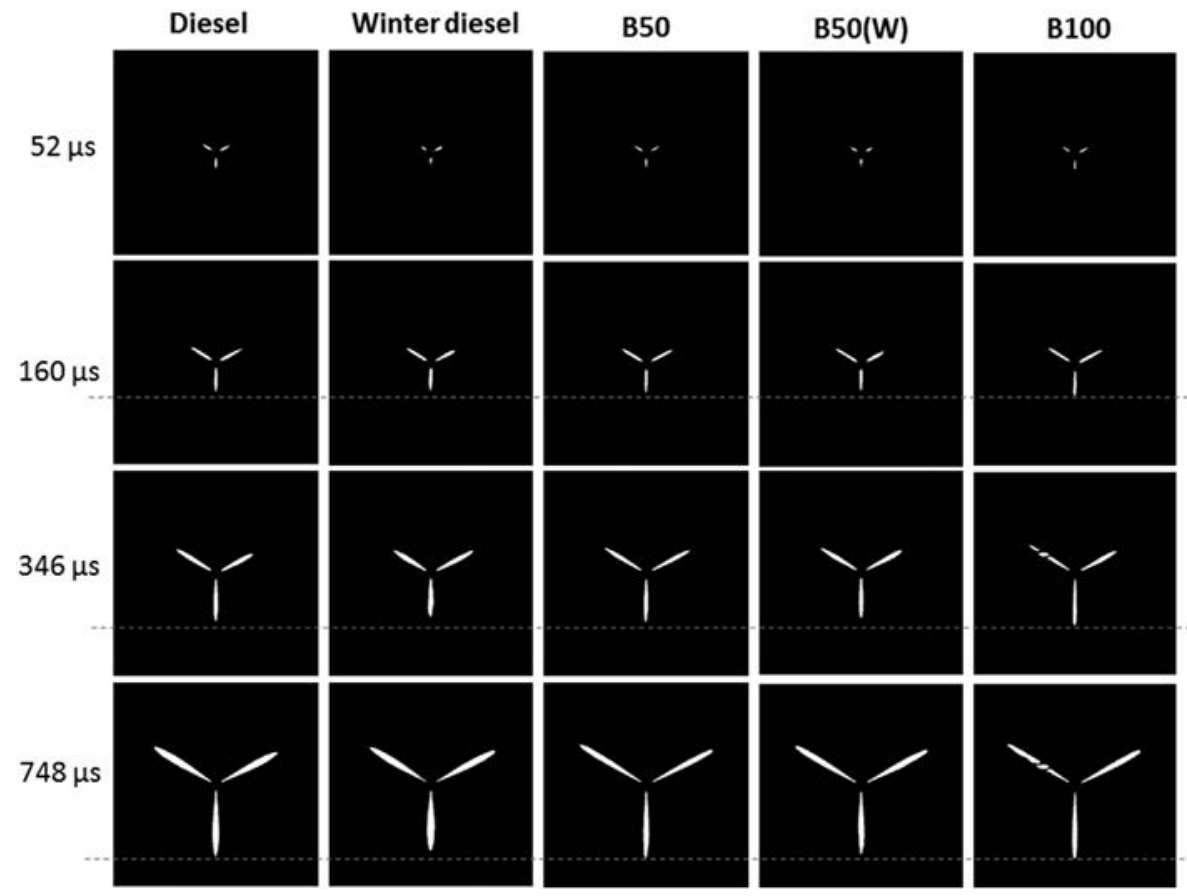

Fig. 11. Comparison of spray development: average image $52 \mu \mathrm{s}, 160 \mu \mathrm{s}, 346 \mu \mathrm{s}$ and $748 \mu \mathrm{s}$ after injection $-\mathrm{T}=-8{ }^{\circ} \mathrm{C}, \mathrm{Pi}=30 \mathrm{MPa}, \mathrm{Pb}=1.2 \mathrm{MPa}$. 

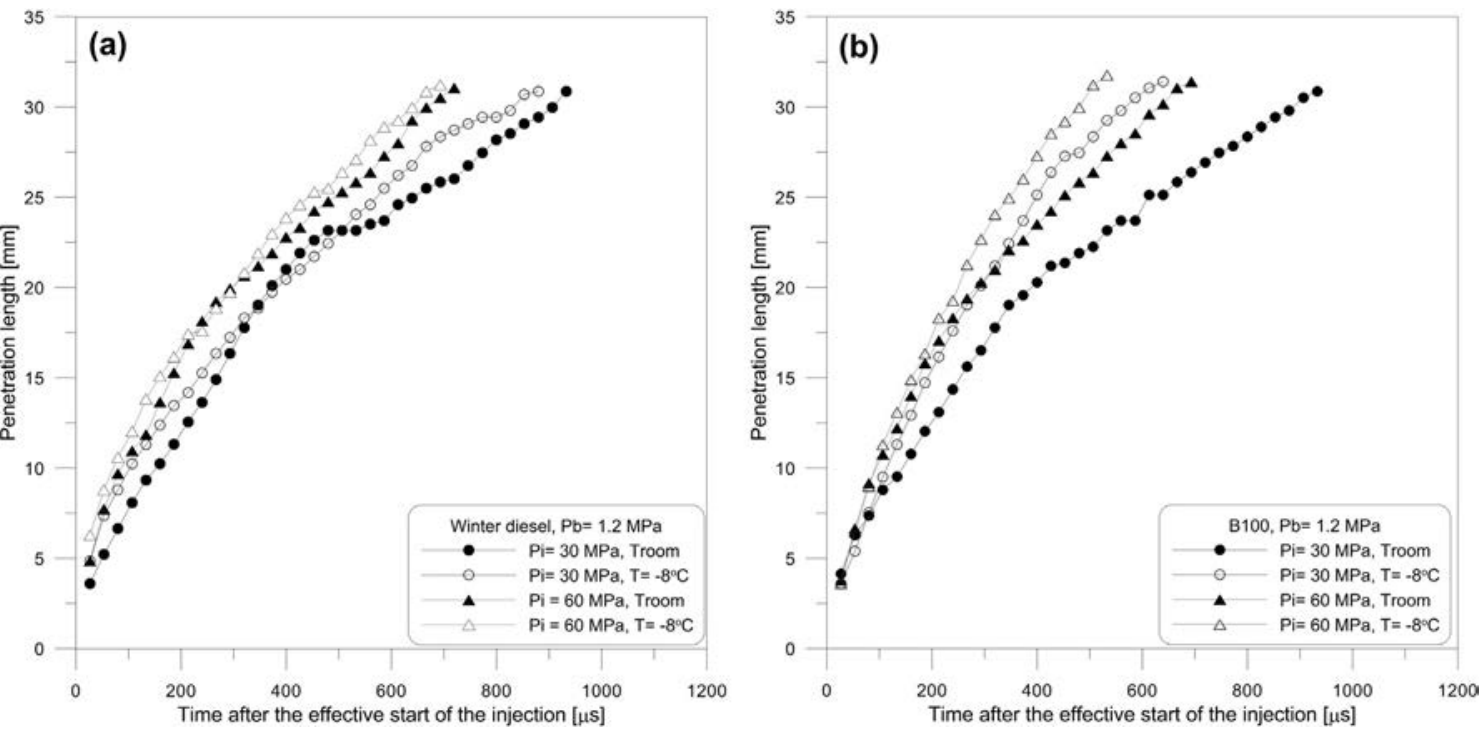

Fig. 12. Mean penetration length on the 3 sprays $-P i=30,60 \mathrm{MPa}, P b=1.2 \mathrm{MPa}$ when (a) winter diesel and (b) B100.
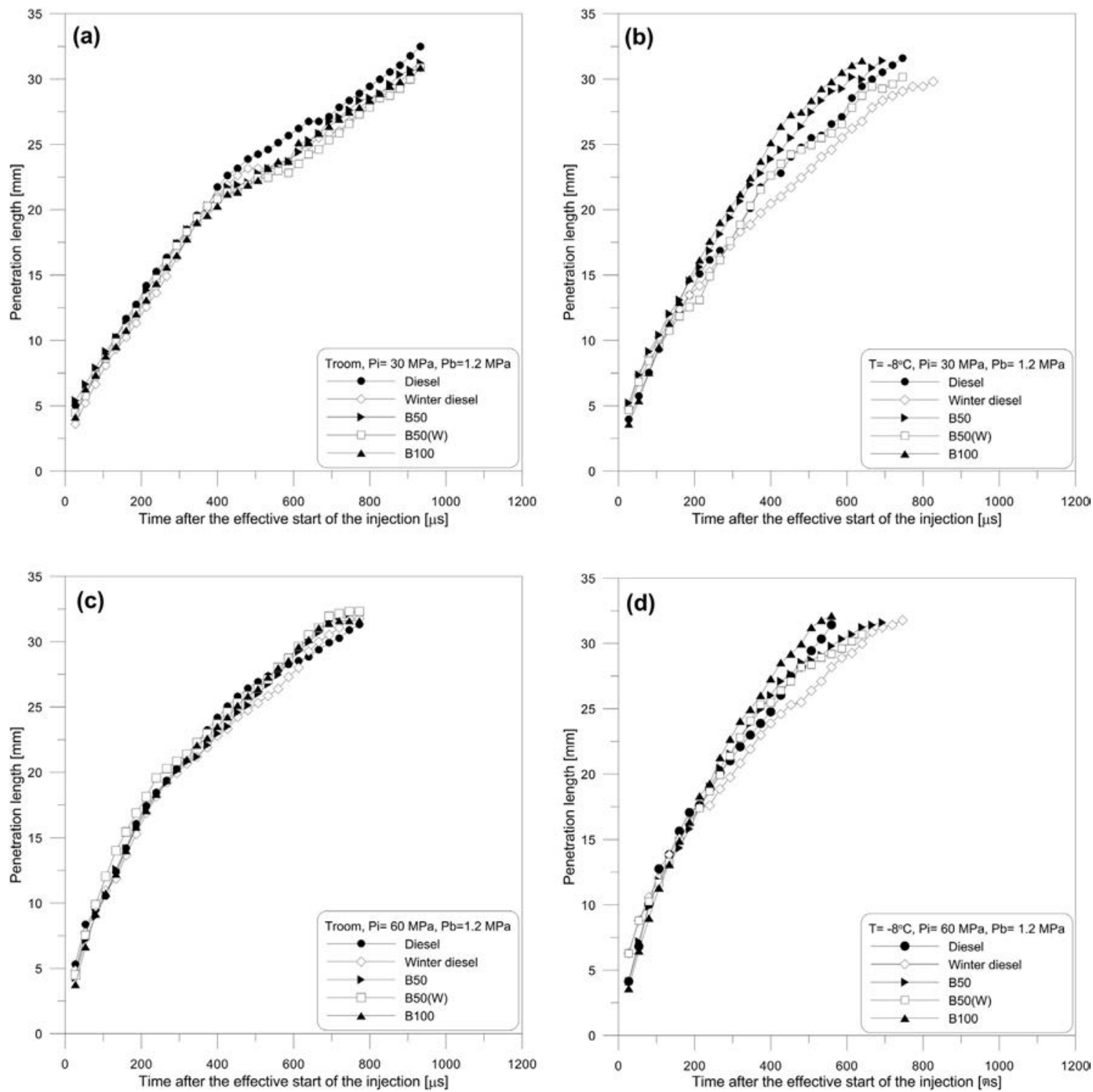

Fig. 13. Mean penetration length all fuel at (a) Troom, $P i=30 \mathrm{MPa}, P b=1.2 \mathrm{MPa}$, (b) $\mathrm{T}=-8{ }^{\circ} \mathrm{C}, P i=30 \mathrm{MPa}, P b=1.2 \mathrm{MPa}$, (c) Troom, $P i=60 \mathrm{MPa}, P b=1.2 \mathrm{MPa}$ and $(\mathrm{d}) \mathrm{T}=-8{ }^{\circ} \mathrm{C}$ $P i=60 \mathrm{MPa}, P b=1.2 \mathrm{MPa}$. 

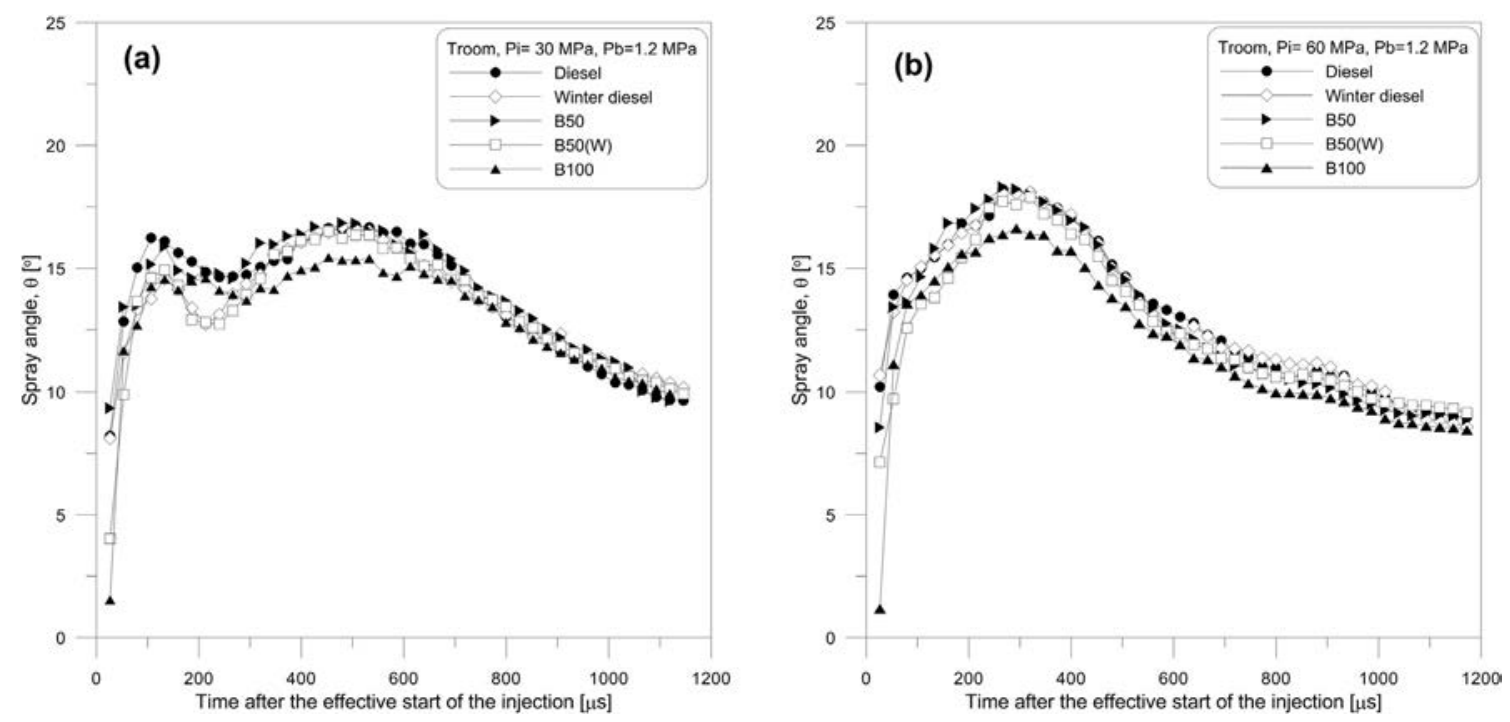

Fig. 14. The spray angle - Troom at (a) $P i=30 \mathrm{MPa}$ and (b) $\mathrm{Pi}=60 \mathrm{MPa}$.

discharge coefficient of the B100 fuel decreases strongly. At $-5{ }^{\circ} \mathrm{C}$ and $-8{ }^{\circ} \mathrm{C}$ the $\mathrm{Cd}$ for fuel blends is not determined only by viscosity. In Fig. 9 (cold temperature), the points are more widely scattered; this dispersion can be explained by the fact that fuel additives for winter diesel and diesel improve the discharge coefficient.

The fuel properties (density and viscosity) of B50(W), which is produced from biodiesel $50 \%$ and winter diesel $50 \%$, are the same as those of B50, produced from biodiesel 50\% and diesel 50\% (Fig. 5). The injection rate behavior at Troom and cold temperature is the same as that of B50 (Fig. 3). Concerning the discharge coefficient, $\mathrm{Cd}$, in quasi steady state period, Fig. 7(a, b) shows that at Troom the values of $C d$ fall between those of diesel and B50, and decrease when the viscosity increases. At cold or positive temperatures the values of $\mathrm{Cd}$ for $\mathrm{B} 50(\mathrm{~W})$ are slightly higher than those of the other diesel fuels and biodiesel blends.

Using the correlation based on the work by Soteriou et al. [26] and developed by Tinprabath et al. [6], the discharge coefficients were compared with the correlation in cold conditions. It applies the generalized Bernoulli principle: the flow rate is estimated by taking the friction loss into account. Rearranging Eqs. (2) and (3), the expression of the discharge coefficient becomes:

$C d=\sqrt{\frac{\Delta P-\Delta P_{C}}{\Delta P}}$

The $C d$ drop is assimilated as a pressure loss. If $C d=1$, it means that there is no pressure loss $\left(\Delta P_{c}=0\right)$. The pressure loss is determined by the following empirical correlation, where $A$ and $B$ are parameters for orifice type loss and $C$ and $D$ for viscous type loss:

$$
\Delta P_{C}=A \cdot v^{D} \cdot \dot{m}_{t h}^{(C . v+B)}
$$

The coefficient values of A, B, C, D are obtained by minimizing the sum of square errors between the correlation and experiment (all temperatures): $\mathrm{A}=40.70, \mathrm{~B}=0.22, \mathrm{C}=-0.0042, \mathrm{D}=0.43$, $\mathrm{R} 2=0.9577$. Fig. 10(a) compares the discharge coefficient correlation from Eq. (9) at pressure differences of 30- $-60 \mathrm{MPa}$, with
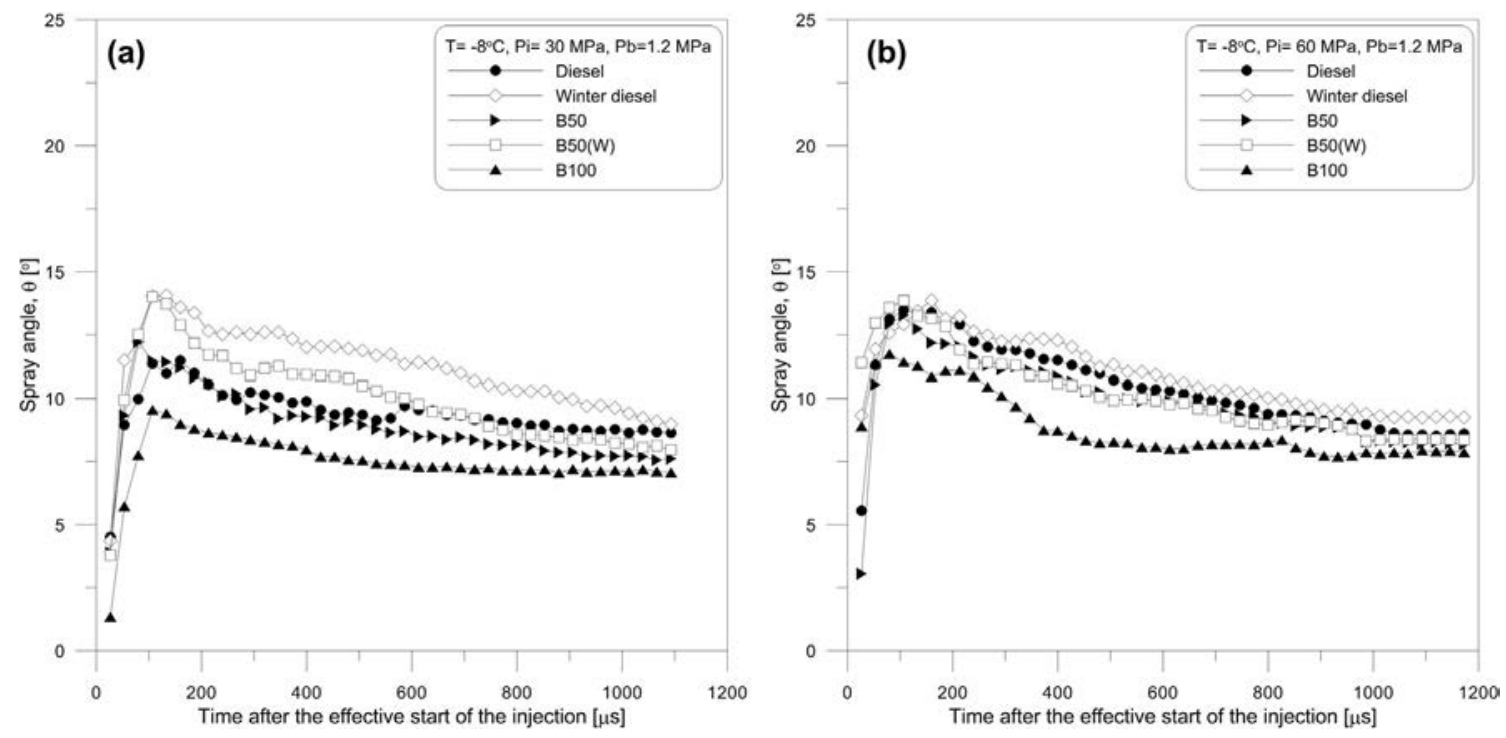

Fig. 15. The spray angle $-\mathrm{T}=-8{ }^{\circ} \mathrm{C}$ at (a) $\mathrm{Pi}=30 \mathrm{MPa}$ and (b) $\mathrm{Pi}=60 \mathrm{MPa}$. 
experimental data for diesel and B100. The average error is $\pm 1.7 \%$. Fig. 10(b) compares the discharge coefficient correlation for all fuels. The correlation predicts the discharge coefficient for the CRI 3.1 injector well.

\subsection{Spray penetration}

The raw images were analyzed with a digital image processing program to determine the spray tip penetration $S$ and spray angle $\theta$. Fig. 11 shows the average image $52,160,346$ and $748 \mu$ s after injection when $P i=30 \mathrm{MPa}$, and $P b=1.2 \mathrm{MPa}$. It can be noted that diesel fuel and biodiesel-blended fuel have a similar spray penetration but that the penetration length with B100 is longer than that of other fuels at the start of injection. These results are similar to those of Chen et al. [18]. At cold temperatures, the spray penetration increases strongly (Fig. 12(b)) but the spray penetration of winter diesel appears to be less sensitive to temperature (Fig. 12(a)). It can be seen that the spray penetration of B100 is the highest of all the fuels. Fig. 13(a, c) shows that the penetration lengths of all fuels at room temperature are not different from the spray penetration behavior.

Fig. 13(b, d) shows that at a temperature $-8{ }^{\circ} \mathrm{C}$, the spray penetration of $\mathrm{B} 100$ is stronger and higher than that of the other fuels, the spray penetration of winter diesel is the lowest, and the spray penetrations of diesel, B50 and B50(W) fall in between. In cold conditions, the spray penetration behavior depends on viscosity: when the viscosity increases strongly due to the cold temperature, the spray penetration also increases strongly. The experimental results show that when winter diesel is used the spray penetration is lower than that of the other fuels although the viscosity is not lower. In the case of $\mathrm{B} 50(\mathrm{~W})$, the spray penetration behavior is similar to that of diesel and B50 (Fig. 13(b, d)).

\subsection{Spray angle}

The spray angle results are shown in Figs. 14 and 15. At room temperature (Fig. 14) the spray angles are almost the same for all fuels, except for B100 which tends to be slightly lower. At cold temperature $\left(-8{ }^{\circ} \mathrm{C}\right)$, the spray angles differ (Fig. 15(a)), with B100 having the lowest spray angle and winter diesel the highest, while diesel fuel lies between B100 and winter diesel. As the injection pressure increases, it can be noted in Fig. 15(b) that the spray angles of diesel, B50 and B50(W) are similar and slightly higher than at $P i=30$ MPa but that the spray angle of B100 remains the lowest. The fact that spray angle behaviors differ under cold conditions is significant, because the spray angle directly affects the combustion [2]. B50(W), which has the same additive as winter diesel, cannot produce as width spray angle as winter diesel. During engine startup, the fact that spray angle behaviors differ under cold conditions for different fuel is significant, because the spray angle directly affects the air-fuel ratio [27], the only fuel that has a larger spray angle behavior is winter diesel.

Fig. 16 shows the average spray angle. The cold temperature reduces atomization of the spray. The spray angle does not depend only on density; it is in fact more sensitive to variations in viscosity. We compared the experimental data with a correlation from Dernotte et al. [13] using Eq. (11). The spray angle versus viscosity is shown in Fig. 16, with the coefficient values $A, B, C, D$ and $E$. They were obtained by minimizing the sum of square errors between the correlation and experiment; $A=0.30, B=0.11, C=-0.13, D=-0.15$ and $E=-0.46, \mathrm{R}^{2}=0.9219$. While several authors (Siebers [27], Hiroyasu [28], Payri et al. [29], Reitz \& Bracco [30]) have proposed correlations to estimate the spray angle based on the injector geometry or injection conditions, only the correlation proposed by Dernotte et al. is in agreement with our results, with a maximum

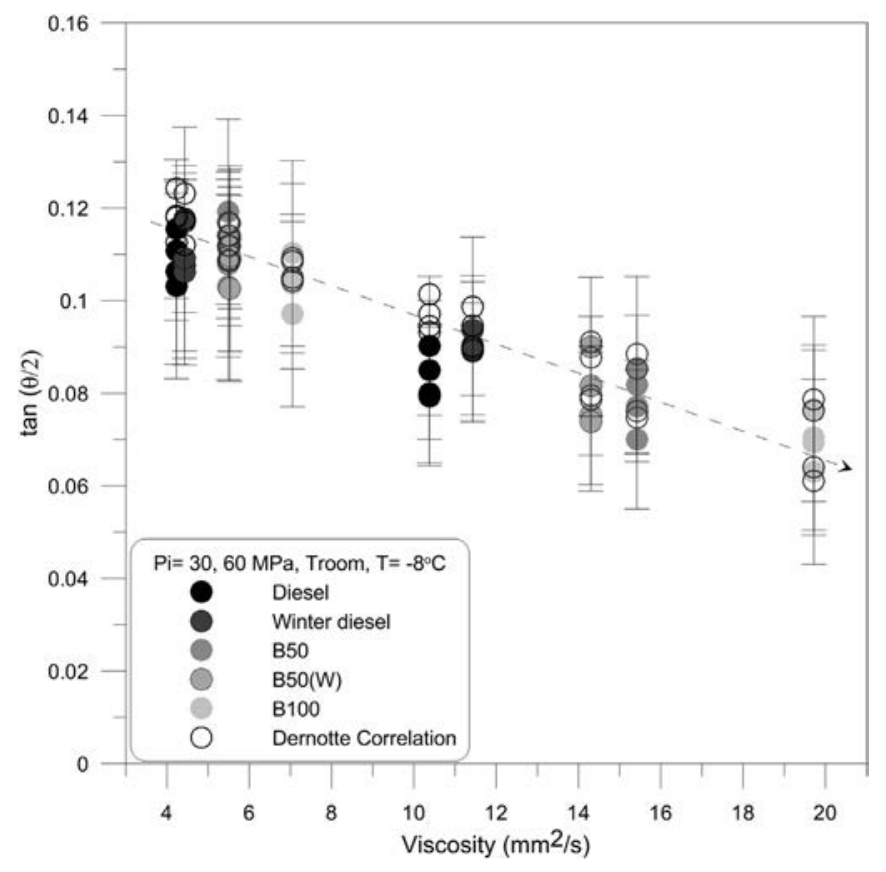

Fig. 16. The average spray angle versus viscosity, experimental data and Dernotte correlation $-\mathrm{Pi}=30,60 \mathrm{MPa}$.

error of $\pm 13.2 \%$.

$\left.\tan \left(\frac{\theta}{2}\right)=A \cdot \frac{\rho_{a}}{\rho_{f}}\right) \cdot \Delta P^{C} \cdot f(v)$

When; $f(v)=\exp \left(D \cdot P^{E} \cdot v\right)$ and $v$ is in $\mathrm{mm}^{2} / \mathrm{s}, \Delta \mathrm{P}$ in MPa.

\section{Conclusions}

The results are compared with data available in the literature. The conclusions of this study are summarized as follows:

(a) Only the fuel viscosity changes the injection duration and hence for the same pulse duration, it also changes the total mass injected. Even if at cold temperature the different additives don't modify the closing delay.

(b) Concerning the performance of the injector shown by the value of the discharge coefficient, two behaviors were observed:

- at positive temperatures or for fuels without additives (B100), the discharge coefficient decreases linearly with increasing viscosity;

- at negative temperatures for fuels with additives (winter diesel, diesel or blends), the viscosity measured at atmospheric pressure is not the only property which modifies the discharge coefficient. The effect of additives cancels out the impact of viscosity and the diesel and fuel blends then have the same discharge coefficient. For winter diesel with other additives the discharge coefficients are better. But when using $\mathrm{B} 50(\mathrm{~W})$ which is produced from biodiesel $50 \%$ and winter diesel $50 \%$, the injection rate are similar to those of diesel and biodiesel blends.

(c) The spray angle is smaller when the temperature decreases or when the viscosity increases.

(d) The spray penetration is longer when the temperature decreases or when the viscosity increases. The sensitivity is different with winter diesel. 
(f) The spray performance (discharge coefficient, length and angle) is better with winter diesel but these benefits are no more visible with $\mathrm{B} 50(\mathrm{~W})$.

\section{Acknowledgements}

This work was cofinanced by the European Union and the European Regional Development Fund. The authors would like to thank you very much Rajamangala University of Technology Phra Nakhon (RMUTP), Thailand for financial support. The authors would like to thank you Julien LEMAIRE for his contribution to the experimental setup.

\section{References}

[1] S.Y. No, How vegetable oils and their derivatives affect spray characteristics in CI engines - a review, At. Sprays 21 (1) (2011) 87-105.

[2] J. Perdiguero, J.L. Jiménez, Sell or not sell biodiesel: local competition and government measures, Renew. Sustain. Energy Rev. 15 (2011) 1525-1532.

[3] A. Demirbas, Progress and recent trends in biodiesel fuels, Energy Convers. Manag. 50 (2009) 14-34.

[4] P. Tinprabath, C. Hespel, S. Chanchaona, F. Foucher, Influence of biodiesel and diesel fuel blends on the injection rate under cold conditions, Fuel 144 (2015) 80-89.

[5] National Biodiesel Board. Low Blends of Biodiesel and Cold Weather Operability. [cit. 2014-03-20] <http://www.biodiesel.org>.

[6] P. Tinprabath, C. Hespel, S. Chanchaona, F. Foucher, Influence of Biodiesel and Diesel Fuel Blends on the Injection Rate and Spray Injection in Non-vaporizing Conditions, 2013. SAE technical paper 2013-24-0032.

[7] A. Sarin, Biodiesel Production and Properties, RSC Publishing, Cambridge, 2012.

[8] S.H. Bang, C.S. Lee, Fuel injection characteristics and spray behavior of DME blended with methyl ester derived from soybean oil, Fuel 89 (2010) 797-800.

[9] X.L.J. Seykens, L.M.T. Somers, R.S.G. Baert, Modeling of common rail fuel injection system and influence of fluid properties on injection process, in: Proceedings of VAFSEP. Dublin. Ireland; July 6-9, 2004.

[10] S. Som, D.E. Longman, A.I. Ramirez, S.K. Aggarwal, A comparison of injection of injector flow and spray characteristics of biodiesel with petrodiesel, Fuel 89 (2010) 4014-4024.

[11] J.M. Desantes, R. Payri, A. Garcia, J. Manin, Experimental study of biodiesel blends' effects on diesel injection processes, Energy Fuels 23 (2009) 3227-3235.

[12] J. Dernotte, C. Hespel, F. Foucher, C. Mounaïm-Rousselle, Influence of physical fuel properties on the injection rate in a diesel injector, Fuel 96 (2012)
$153-160$.

13] J. Dernotte, C. Hespel, F. Foucher, C. Mounaïm-Rousselle, Influence of fue properties on the diesel injection process in non-vaporizing conditions, At Sprays 22 (6) (2012) 461-492.

[14] R. Payri, F.J. Salvador, J. Gimeno, J. Morena, Study of cavitation phenomena based on a technique for visualizing bubbles in a liquid pressurized chamber, Fuel 30 (2009) 768-777.

[15] S.H. Park, H.K. Suh, C.S. Lee, Effect of cavitating flow on the flow and fuel atomization characteristics of biodiesel and diesel fuels, Energy Fuels 22 (2008) 605-613.

[16] B. Kegl, Biodiesel usage at low temperature, Fuel 87 (2008) 1306-1317.

17] Y. Gao, J. Deng, C. Li, F. Deng, Z. Liao, Z. Wu, L. Li, Experimental study of the spray characteristics of biodiesel based on inedible oil, Biotechnol. Adv. 27 (2009) 616-624.

[18] P.C. Chen, W.C. Wang, W.L. Roberts, T. Fang, Spray and atomization of diese fuel and its alternatives from a single-hole injector using a common rail fue injection system, Fuel 103 (2012) 850-861.

[19] R. Payri, F.J. Salvador, J. Gimeno, G. Brach, Effect of fuel properties on diese spray development in extreme cold conditions, in: Proc. IMechE, vol. 222. 2008, pp. 1743-1753. Part D; J. Automobile Engineering.

[20] R. Payri, J.M. Garcia, F.J. Salvador, J. Gimeno, Using spray momentum flux measurements to understand the influence of diesel nozzle geometry on spray characteristics, Fuel 84 (2005) 551-561.

[21] W. Bosch, The Fuel Rate Indicator: a New Measuring Instrument for Display of the Characteristics of Individual Injection, 1996. SAE technical paper 960749

[22] N. Otsu, A threshold selection method from gray-level histograms, IEEE Trans. Syst. Man. Cyber 1 (1979) 62-66.

[23] Anton Paar GmbH, Instruction Manual SVM 3000 Stabinger Viscometer, 2005 Austria.

[24] M.R. Riazi, Characterization and Properties of Petroleum Fractions, second ed. ASTM International, Danvers, 2007.

[25] C. Vergnes, F. Foucher, C. Mounaïm-Rousselle, Discharge coefficient for a diesel injector during cold starting conditions, At. sprays 19 (7) (2009) 621-631.

[26] C. Soteriou, M. Lambert, S. Zuelch, D. Passerel, The flow characteristics of high efficiency diesel nozzles with enhanced geometry holes, in: THIESEL Conference on Thermo and Fluid Dynamics in Diesel Engines; Valencia; Spain; September 13-15, 2006.

[27] D.L. Siebers, Scaling Liquid-phase Fuel Penetration in Diesel Sprays Based on Mixing- Limited Vaporization, 1999. SAE paper 1999-01-0528.

[28] H. Hiroyasu, M. Arai, Structures of Fuel Sprays in Diesel Engines, 1990. SAE paper 900475

[29] R. Payri, F.J. Salvador, J. Gimeno, R. Novella, Flow regime effects on noncavitating injection nozzles over spray behaviour, Int. J. Heat Fluid Flow 32 (2010) 273-284.

[30] R.D. Reitz, F.B. Braco, On the Dependence of Spray Angle and Other Spray Parameters on Nozzle Design and Operating Conditions, 1979. SAE Pape 790494. 